\section{P-5 DEVELOPING A SERVICE TO SUPPORT FAMILIES TO PREPARE THEIR CHILDREN FOR THE DEATH OF A PARENT}

Nicola Pereira, Lisa Carter. St Luke's Hospice, Plymouth, UK

10.1136/bmjspcare-2018-hospiceabs.30

Background It was identified that parents didn't know how to begin conversations about death and dying with their children and they were often overlooked by professionals concerned about getting it wrong. This resulted regularly in patients with young children coming into an inpatient hospice for terminal care with children unprepared for their death, leading to concerns about the longer term effects on the mental health and resilience of these children in the future (Crook \& Eliot, 1980).

An in-house service to provide bespoke family-centred prebereavement support for families where a parent or significant adult had received a terminal diagnosis was developed. It was acknowledged that not all children need complex or long term interventions (Kennedy, McIntyre, Worth et al., 2008). A dedicated children/families support worker was recruited.

Aim To evaluate the service which was piloted over six months.

Method Interventions with children included individual one-toone support, making worry dolls and memory boxes plus liaison with schools and other services. Adult interventions involved advising and supporting parents about the language and timing of conversations, need for honesty and helping with letter writing and mummy diaries.

Results 50 children were supported during the pilot. Most of the interventions occurred at home whilst the parent was still well. When the time came for admission to the inpatient unit the family were prepared and familiar with the service and the staff. Feedback was exceptionally positive: 'It was important for us to know that $\mathrm{L}$ was there to hold our hand when we need it'. Twenty-four children were discharged from the service and six accepted onward referral to local children's bereavement services.

Conclusion Parents felt empowered to provide their children with age appropriate, timely information. Children were well adjusted to the death of the adult and there was less need for conventional bereavement services in the period immediately after death.

\section{\begin{tabular}{|l|l}
\hline P-6 MUDDY FOOTPRINTS. GRIEF IN THE FOREST \\
\hline
\end{tabular}}

Rachael Courage. Dorothy House Hospice Care, Winsley, Bradford on Avon, UK

\subsection{6/bmjspcare-2018-hospiceabs.31}

Muddy Footprints, funded by Children in Need, is an innovative new model based on the principles of social learning; supporting children and their families who have experienced parental bereavement. Run in partnership with a local forest school, Muddy Footprints aims to be an inclusive and easy to access therapeutic approach. In opposition to methodologies which separate bereaved children from their remaining parent, this model keeps the remaining family together. The day takes place in the naturally therapeutic environment of the woods and allows parentally bereaved families to come together and share their stories, reducing isolation and normalising their experience.
The day starts around the campfire where families introduce themselves, and name the person they have come to remember. A range of woodland craft activities designed to offer remembrance tools, such as lantern making, are available for families throughout the day. However the true magic happens when the children create their own activities; either with their new group of friends, digging a remembrance island into the mud or building a den; just their own family, swinging in a hammock, or cooking in the mud kitchen; or taking some time on their own to sit under a tree or toast a marshmallow. This non-directive approach allows the children to both access and shape the support that best meets their needs.

The adults talk about how relaxing the day is, which as a bereaved and therefore often single parent is very precious. All family members report the value of having protected time together to re-group, talk and play, away from the day-to-day pressures and distractions of life, and the children talk about making friends with others who understand. But by far, the main comment we receive at the end of the day is ' $I$ want to come back again'!

\section{P-7 THE ATLAS PROGRAMME FOR SCHOOLS: SUPPORTING CHILDREN TO NAVIGATE THEIR WAY THROUGH BEREAVEMENT}

Katherine Birch, Hannah Bridge. Compton Care, Wolverhampton, UK

10.1136/bmjspcare-2018-hospiceabs.32

By the age of 16 , almost eight out 10 young people have experienced the death of a close friend or relative. The negative impact of unresolved childhood bereavement may reduce academic achievement, increase risk of offending behaviour, teenage pregnancy and developing mental health difficulties (Ribbens McCarthy with Jessop, 2005; Akerman \& Statham, 2014).

Bereaved young people may find it difficult to talk to anyone about their experiences. With children spending over six hours a day in school, schools are a key source of support, constancy and consistency when families experience the turbulence of bereavement.

A common theme in the research literature is that there are a wide range of outcomes for children who have experienced a close bereavement. All children and families are unique and have different experiences of bereavement and grief, and responses to them. A qualitative study (Abdelnoor \& Hollins, 2004) found that while some children took a 'restorative approach' to school life, preferring to deal with loss-related issues elsewhere, others described chaos and distress in school following the bereavement. It is essential therefore that staff working within schools are confident in supporting bereaved young people and understand how bereavement impacts at different stages of the lifecycle.

This paper discusses the initial outcomes from the ATLAS programme, established in 2017 to help schools support pupils as they navigate their way through their experiences of bereavement. Atlas aims to:

- Raise awareness of the extent and effects of bereavement on young people

- Support schools in the Wolverhampton area to develop effective bereavement policy and practice 